\title{
An unusual case of central diabetes insipidus \& hyperglycemic hyperosmolar state following cardiorespiratory arrest
}

\author{
Muhammad Qamar Masood ${ }^{1 *}$, Suneel Kumar ${ }^{2}$, Ali Asghar ${ }^{1}$ and Abdul Jabbar ${ }^{1}$
}

\begin{abstract}
Background: We are describing an unusual case of severe hyperglycemia and hypernatremia, resistant to treatment.

Case presentation: A thirty year old female with adenocarcinoma of rectum was admitted with increasing lethargy, headache and drowsiness. She deteriorated rapidly and had cardiac arrest, following which she remained comatose. Her initial serum glucose and sodium were normal, but after receiving dexamethasone and mannitol, the serum glucose progressively increased to $54.7 \mathrm{mmol} / \mathrm{L}$ and sodium to $175 \mathrm{mmol} / \mathrm{L}$, despite receiving very high dose of intravenous (IV) insulin infusion. She was evaluated for diabetes insipidus because of continued polyuria even after correction of hyperglycemia. Her serum osmolality was $337 \mathrm{mmol} / \mathrm{kg}$, and urine osmolality was $141 \mathrm{mmol} / \mathrm{kg}$ which rose to $382 \mathrm{mmol} / \mathrm{kg}$, after receiving $4 \mathrm{mcg}$ of IV Desmopressin.

Conclusion: Our patient developed central diabetes insipidus post cardiac arrest and severe dehydration because of diabetes insipidus. Stress of critical illness, dehydration, dexamethasone and IV dextrose infusion were likely responsible for this degree of severe and resistant to treatment hyperglycemia.
\end{abstract}

Keywords: Central, Diabetes, Insipidus, Hyperosmolar, Hyperglycemic, State, Cardiopulmonary, Arrest

\section{Background}

Central diabetes insipidus (DI) is characterized by decreased release of antidiuretic hormone (ADH), resulting in a variable degree of polyuria. Lack of $\mathrm{ADH}$ can be caused by neurosurgery or trauma, primary or secondary tumors, infiltrative diseases, idiopathic DI, hypoxic encephalopathy or severe ischemia. Cases of DI are described in literature in association with cardiopulmonary arrest, severe hypoxia secondary to drug induced respiratory failure as well as carbon monoxide poisoning [1-3].

\section{Case presentation}

Our patient was a 30 year old female recently diagnosed with adenocarcinoma of rectum with metastasis to inguinal lymph nodes. She underwent diversion colostomy. The procedure and hospital course was uneventful, and she was

\footnotetext{
* Correspondence: qamar.masood@aku.edu

${ }^{1}$ Department of Medicine, Section of Endocrinology, Aga Khan University Hospital, Stadium Road, P.O. Box 3500, Karachi 74800, Pakistan Full list of author information is available at the end of the article
}

discharged two days later with further plan for chemotherapy and radiation therapy two weeks post surgery.

Twelve days later, she presented in emergency department at 2230 hours with complains of headache and progressive lethargy. She was drowsy but arousable; otherwise her neurological and systemic examination was unremarkable. Laboratory data showed leucocytosis with left shift, mild hypercalcemia and hypokalemia. Serum sodium and glucose were normal (Table 1). She was given IV fluids with normal saline, potassium replacement and Pamidronate infusion. IV hydrocortisone $200 \mathrm{mg}$, Ceftriaxone and acyclovir were given emperically. MRI Brain and CSF analysis were normal.

Next day, she deteriorated rapidly with increasing restlessness, incoherent speech, followed by tonic clonic seizure. Later in the evening, she had cardiac arrest for which cardiopulmonary resuscitation (CPR) was done for three minutes.

She remained comatose after this episode. She was loaded with Phenytoin and started on IV dexamethasone and mannitol. She was also given isotonic saline boluses,

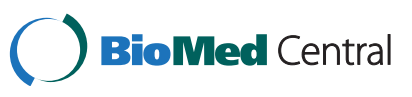


Table 1 Laboratory parameters

\begin{tabular}{|c|c|c|c|c|c|c|}
\hline \multirow[t]{2}{*}{ Test } & \multirow[t]{2}{*}{ Emergency room } & \multirow[t]{2}{*}{ Day 1} & \multicolumn{2}{|c|}{ Day 2} & \multicolumn{2}{|r|}{ Day 3} \\
\hline & & & 0600 hours & 1500 hours & After IV fluids & After desmospressin \\
\hline Glucose $(\mathrm{mmol} / \mathrm{L})$ & 6.7 & "Hi" on CBG & "Hi" on CBG & 54.7 & 9.2 & \\
\hline Sodium (mmol/L) & 146 & 165 & 170 & 175 & 164 & 140 \\
\hline Potassium (mmol/L) & 2.0 & 3.9 & 2.4 & 2.8 & 4.7 & 5.3 \\
\hline Chloride (mmol/L) & 108 & 130 & 145 & & 143 & \\
\hline Bircarbonate $(\mathrm{mmol} / \mathrm{L})$ & 23.8 & 20.7 & 19.7 & & 17.7 & \\
\hline Serum Osmolality (mmol/Kg) & & & & & 337 & 294 \\
\hline Urine Osmolality $(\mathrm{mmol} / \mathrm{Kg})$ & & & & & 141 & 382 \\
\hline Spot Urine $\mathrm{Na}$ (mmol/L) & & & & & 52 & 136 \\
\hline BUN (mmol/L) & 7.8 & 9.6 & 10 & & 2.5 & \\
\hline Creatinine $(\mu \mathrm{mol} / \mathrm{L})$ & 70.7 & 88.4 & 97 & & 44.2 & \\
\hline Calcium (mmol/L) & 2.75 & 2.92 & & & 2.20 & \\
\hline Total Intake (Liters per 24 hours) & & 0.6 (Only 3 hours) & 8 & & 18.8 & \\
\hline Urine output (Liters per 24 hours) & & 1.5 (Only 3 hours) & 6 & & 7.2 & \\
\hline
\end{tabular}

plasma expanders (gelatin polypeptide), and dopamine and norepinephrine infusion.

On the same day, her capillary blood glucose (CBG) was noted to be more than $16 \mathrm{mmol} / \mathrm{L}$. She was started on IV insulin infusion at 10 units per hour via insulin syringe pump, which was progressively increased but CBG remained HI ( $>27 \mathrm{mmol} / \mathrm{L})$ on glucometer. After 24 hours on IV insulin infusion, her serum glucose (SG) was $54.7 \mathrm{mmol} / \mathrm{L}$ while she was still on 60 units per hour IV insulin infusion. Her serum sodium (Na) after cardiac arrest rose to $165 \mathrm{mmol} / \mathrm{L}$. She was given IV Dextrose water 5\% (D5W). Despite that, next day $\mathrm{Na}$ reached to $170 \mathrm{mmol} / \mathrm{L}$ while SG was $54.7 \mathrm{mmol} / \mathrm{L}$ (see Table 1). She was making urine about 250-400 mL/hour while receiving similar amount of IV fluids.

An assessment of hyperosmolar hyperglycemic state with severe dehydration was made. Glucocorticoids and stress of acute illness were thought to be responsible for initial rise in glucose and later osmotic diuresis because of mannitol and glycosuria resulted in severe dehydration and hypernatremia.

Patient was treated with IV $0.45 \%$ saline and D5W (total of eight liters overnight). After receiving fluids, her CBG gradually decreased to $9.2 \mathrm{mmol} / \mathrm{L}$ and insulin dose was titrated down to 18 units per hour. Her Na also decreased to $164 \mathrm{mmol} / \mathrm{L}$. However after achieving near normal glycemia and alleviating osmotic diuresis, her urine output remained elevated (approximately $400 \mathrm{~mL} /$ hour). She was then evaluated for diabetes insipidus.

Her serum osmolality was $337 \mathrm{mmol} / \mathrm{kg}$ and urine osmolality was $141 \mathrm{mmol} / \mathrm{kg}$. Urine osmolality rose to $382 \mathrm{mmol} / \mathrm{kg}$ after receiving $4 \mathrm{mcg}$ of IV desmopressin. After desmopressin, her urine output dropped and serum $\mathrm{Na}$ gradually improved to $140 \mathrm{mmol} / \mathrm{L}$. After desmopressin, her insulin requirement substantially decreased and she was taken off IV insulin. After correction of her metabolic derangements, she remained comatose and totally dependent on ventilator. At that point, the family decided to withdraw the support.

\section{Discussion}

We believe that hypoxic damage to the posterior pituitary and/or hypothalamus during cardiac arrest was responsible for the central DI in this patient. A urine osmolality of $141 \mathrm{mmol} / \mathrm{kg}$ when serum osmolality was $337 \mathrm{mmol} / \mathrm{kg}$ was diagnostic of DI and response to desmopressin confirmed the central cause.

DI following cardiorespiratory arrest is a rare event and has been described in post cardiopulmonary arrest patients [1-4]. In the cases described by Udoshi et al. [4], no lesion was found in the posterior pituitary and hypothalamus on autopsy, however the second patient had infarction of anterior pituitary. Hypothalamic dysfunction i.e. wide fluctuations in heart rate, blood pressure and body temperature were noted in both patients.

DI has also been reported with pituitary tumor apoplexy [5], after moderate to severe traumatic brain injury [6], acute sheehan syndrome [7] and in patients with long standing hypopituitarism secondary to sheehan syndrome [8].

A case of non-ketotic hyperglycemic coma in an 18 year old male, with previously undiagnosed diabetes mellitus, was described in association with hemorrhagic pituitary apoplexy. MRI in this patient revealed a heterogeneous mass, a prolactinoma, arising from an expanded sella turcica and extending into the suprasellar cistern [9]. In the two cases described by Udoshi et al. [4], both developed profound hyperglycemia. 
Stress and drug induced hyperglycemia was culminated in profound and resistant to treatment hyperglycemia in our patient. This was due to extreme dehydration secondary to DI, and the hyperglycemia mainly responded to fluid resuscitation.

\section{Conclusion}

Our patient developed central DI post cardiac arrest manifested as hypernatremia and severe dehydration, responsible for this degree of severe and resistant to treatment hyperglycemia.

\section{Consent}

Written informed consent was obtained from the patient's brother (next of kin) for publication of this case report. A copy of the written consent is available for review by the Series Editor of this journal.

\footnotetext{
Abbreviations

IV: Intravenous; DI: Diabetes insipidus; ADH: Antidiuretic hormone; CPR: Cardiopulmonary resuscitation; CBG: Capillary blood glucose; SG: Serum glucose; Na: Serum sodium; D5W: Dextrose water 5\%.
}

\section{Competing interests}

The authors declare that they have no competing interests.

\section{Authors' contributions}

QM gave the concept of research paper, and critically reviewed the manuscript. SK led the acquisition of data, review of literature, and drafted the manuscript. AA reviewed the manuscript. AJ critically reviewed the manuscript. All authors read and approved the manuscript.

\section{Authors' information}

QM is fellow of the American College of Physicians \& the American College of Endocrinology. He is Assistant Professor in Diabetes, Endocrinology \& Metabolism, Department of Medicine, Aga Khan University Hospital. He was involved in the medical management of the patient. SK is fellow of the College of Physicians \& Surgeons of Pakistan. He is Senior Instructor in Endocrinology, Department of Medicine, Sultan Qaboos University Hospital. He was involved in the medical management of the patient. AA is member of the Royal Colleges of Physicians of the United Kingdom. He is Fellow in Endocrinology, Diabetes \& Metabolism, Department of Medicine, Aga Khan University Hospital. He was involved in the medical management of the patient. AJ is fellow of the Royal College of Physicians of London. He is Professor in Diabetes, Endocrinology \& Metabolism, Department of Medicine, Aga Khan University Hospital.

\section{Author details}

${ }^{1}$ Department of Medicine, Section of Endocrinology, Aga Khan University Hospital, Stadium Road, P.O. Box 3500, Karachi 74800, Pakistan. ${ }^{2}$ Department of Medicine, Endocrinology, Sultan Qaboos University Hospital, Muscat, Oman.

Received: 25 April 2013 Accepted: 12 August 2013

Published: 16 August 2013

\section{References}

1. Rothschild M, Shenkman L: Diabetes insipidus following cardiorespiratory arrest. JAMA 1977, 238(7):620-621.

2. Arisaka O, Arisaka M, Ikebe A, Niijima S, Shimura N, Hosaka A, Yabuta K: Central diabetes insipidus in hypoxic brain damage. Childs Nerv Syst 1992, 8(2):81-82.

3. Beasley EW 3rd, Phillips LS: Polyuria and refractory hypernatremia after cardiopulmonary arrest. Am J Med 1987, 82(2):347-349.

4. Udoshi MB, Trivedi AD, Desai RC, Lichtenstein E: Diabetes insipidus following cardiorespiratory arrest. J Natl Med Assoc 1981, 73(9):797-800.
5. Sweeney AT, Blake MA, Adelman LS, Habeebulla S, Nachtigall LB, Duff JM, Tully GL 3rd: Pituitary apoplexy precipitating diabetes insipidus. Endocr Pract 2004, 10(2):135-138.

6. Agha A, Thornton E, O'Kelly P, Tormey W, Phillips J, Thompson CJ: Posterior pituitary dysfunction after traumatic brain injury. $J$ Clin Endocrinol Metab 2004, 89(12):5987-5992.

7. Robalo R, Pedroso C, Agapito A, Borges A: Acute Sheehan's syndrome presenting as central diabetes insipidus. BMJ Case Rep 2012. doi:10.1136/bcr-2012-007022.

8. Atmaca H, Tanriverdi F, Gokce C, Unluhizarci K, Kelestimur F: Posterior pituitary function in Sheehan's syndrome. Eur J Endocrinol 2007, 156(5):563-567.

9. Kamboj MK, Zhou P, Molofsky WJ, Franklin B, Shah B, David R, Kohn B: Hemorrhagic pituitary apoplexy in an 18 year-old male presenting as non-ketotic hyperglycemic coma (NKHC). J Pediatr Endocrinol Metab 2005, 18(6):611-615.

doi:10.1186/1756-0500-6-325

Cite this article as: Masood et al:: An unusual case of central diabetes insipidus \& hyperglycemic hyperosmolar state following cardiorespiratory arrest. BMC Research Notes 2013 6:325.

\section{Submit your next manuscript to BioMed Central and take full advantage of:}

- Convenient online submission

- Thorough peer review

- No space constraints or color figure charges

- Immediate publication on acceptance

- Inclusion in PubMed, CAS, Scopus and Google Scholar

- Research which is freely available for redistribution 